(C) Dereito Vol.29, n02:107-112 (Xullo-Decembro, 2020) • ISSN 1132-9947

\title{
NASARRE AZNAR, S., Los años de la crisis de la vivienda. De las hipotecas subprime a la vivienda colaborativa, Valencia, Tirant lo Blanch, 2020, 656 pp.
}

\section{DOI: http://dx.doi.org/10.15304/dereito.29.2.6958}

El examen completo de la crisis habitacional 2007-2020 y sus soluciones en un contexto comparado: esta es la propuesta que nos presenta el Prof. Dr. Sergio Nasarre Aznar en su última monografía, titulada "Los años de la crisis de la vivienda. De las hipotecas subprime a la vivienda colaborativa". Esta obra ha sido elaborada durante ocho años y ha contado con la realización de una estancia de investigación en la Universidad de Duke en 2011, lo que atestigua la calidad científica y rigor del libro que recensionamos; estamos, sin duda, ante la obra de referencia en materia de vivienda publicada en los últimos tiempos. Dos ejes y diversos neologismos centran el examen jurídico de la crisis de la vivienda: por una parte, los problemas de acceso y asequibilidad, los abusos bancarios y la titulización hipotecaria con refinanciación indefinida, junto con los lanzamientos o la "pérdida forzosa" de la vivienda, a modo de origen o síntoma; y, por otra parte, la legislación motorizada y "dispersa" -civil y administrativa- como solución, o jarabe indigesto por su escasa reflexión, precedida de la "robinprudencia" o jurisprudencia "robinhoodiana" para el deudor hipotecario, aderezada por el Tribunal de Justicia de la Unión.

A grandes males, grandes remedios; y a exigua eficacia del American Dream o la generalización de la vivienda en propiedad, el Dr. Nasarre ofrece soluciones realistas de Derecho comparado para despertar del sueño, mediante una redistribución de los regímenes de tenencia para reequilibrar el binomio seguridad-asequibilidad. Todo ello para enmendar la shapeless housing o vivienda desdibujada, derivada de una mala planificación de la política de vivienda, a la que este libro aporta numerosas alternativas y propuestas nutridas con una extensa y completa bibliografía. La obra se distribuye en seis Capítulos, de los cuales los tres primeros analizan el origen de la crisis hipotecaria, la titulización hipotecaria en Estados Unidos y la globalización de dicha crisis, los dos siguientes examinan los efectos de dicha crisis en España y formulan soluciones de Derecho comparado algunas ya articuladas a modo de legal transplant-, y el último contiene unas reflexiones finales.

En el primer Capítulo, "Los fundamentos de la crisis: el mercado hipotecario y la vivienda", el Dr. Nasarre sitúa el germen de la crisis habitacional en la generalización de la propiedad como régimen de tenencia. Ello se debe a una premisa cierta: la seguridad y estabilidad que proporciona la propiedad en comparación con el arrendamiento, a cuya profusa explicación nos remitimos. Sin embargo, como advierte el Dr. Nasarre, el arrendamiento constituye otro régimen de tenencia disponible, no la alternativa a la propiedad. La regulación del arrendamiento de vivienda, desarrollada en diversos Estados europeos a principios de 1980, liberalizó el mercado del alquiler reduciendo esta tenencia mayoritaria mediante una desprotección progresiva del arrendatario, cuya máxima expresión es el assured shorthold 
tenancy del Reino Unido: un arrendamiento de seis meses de duración asegurada en el curso de un año, cuyas rentas completas se pagan por adelantado, y con desahucio sin causa a partir del sexto mes.

A pesar de la seguridad que proporciona la vivienda en propiedad, resulta difícil garantizar la misma estabilidad en la solvencia del deudor hipotecario que la adquiere. Por un lado, debido a los abusos bancarios derivados de la inobservancia del deber de información precontractual y el control de transparencia. Por otro lado, por la insolvencia de los consumidores afectados por la crisis bancaria y económica surgida con el estallido de la burbuja inmobiliaria estadounidense en 2007, cuya afectación en España se negaba dos años después, como recuerdan los "brotes verdes" citados al inicio del Capítulo Cuarto. En palabras del Dr. Nasarre, se pasó del "Sueño Americano" a la "Pesadilla Americana" por la concesión masiva de préstamos hipotecarios de baja calidad y su refinanciación indefinida, las ejecuciones hipotecarias y lanzamientos de deudores hipotecarios insolventes, el incremento de las viviendas vacías, así como la pérdida de valor de los inmuebles y, por tanto, de las garantías hipotecarias. A nivel normativo, buena parte de la crisis hipotecaria surgió por la posibilidad de refinanciación indefinida de las hipotecas subprime sin cesión civil, lo que desplaza el riesgo de la contraparte a un tercero mediante derivados financieros, alimentando la voracidad bancaria y la burbuja inmobiliaria. Por lo que respecta a España, el Dr. Nasarre advierte que la Ley 5/2015, de 27 de abril, de fomento de la financiación empresarial desatiende la naturaleza de los special purpose vehicle, y si se produce cesión civil en las participaciones o certificados de transmisión, lo que resulta esencial para enmendar los desajustes de la titulización hipotecaria indicados.

El Capítulo Segundo, titulado "La problemática hipoteca norteamericana", y el Capítulo Tercero, denominado "La problemática titulización hipotecaria norteamericana. La globalización de la crisis", centran el examen de la "originación" de la mal llamada "hipoteca norteamericana"; como señala el Dr. Nasarre, existen más de 3.000 tipos distintos de constituir una hipoteca. A pesar de su variedad, todos ellos adolecen de los mismos defectos: falta de seguridad preventiva pública suficiente; carencia de cesión y ejecución eficientes; y la titulización para la traslación del riesgo. Dicha titulización constituye la expresión más evidente de un sistema que confió demasiado en el "Too big to fail" o las redes de protección de los riesgos derivados de esta operación financiera. Siguiendo con la estructura de la obra, el Capítulo Segundo examina críticamente la hipoteca norteamericana, que adolece de unos vicios originarios basados en la ausencia de control y su atomización. Ello ocasiona una vulnerabilidad frente a crisis locales que requiere que otras entidades adquieran dichos préstamos para liberarles del riesgo. Esta refinanciación ilimitada incentiva a las entidades financieras a su comercialización indebida, a sabiendas de la falta de solvencia del deudor, por la supresión del riesgo. Ello redunda en una protección deficiente del consumidor frente al sobreendeudamiento: se encuentra especialmente en las piggy-back mortgages, el examen de su historial crediticio, junto con problemas de índole registral. 
A esta laxitud, se suma la posibilidad de ceder créditos hipotecarios mediante lo que el Dr. Nasarre califica con acierto de "distorsión generalizada del Derecho". Esta consiste en facilitar la cesión de créditos hipotecarios para su titulización, favoreciendo el MERS como Registro de la Propiedad privado gestionado por la "industria hipotecaria"; a diferencia de un Registro público, el MERS entraña opacidad en las transacciones para la titulización, problemas de evasión fiscal y conflictos de intereses por dicha titulización. Ello cristalizó en la constitución de seguros privados de los títulos de propiedad de las fincas y la falsificación de las cesiones de créditos, conocida como robo-signing scandal. Pero los problemas no acaban aquí, pues, como bien indica el Dr. Nasarre, la ejecución hipotecaria americana adolece de ineficacia, regulación suficiente, y escasas alternativas razonables al lanzamiento, como la deed in lieu, el short sale, la friendly foreclosure, la subasta ante el sheriff y la equity skimming. Por ello, propone otra solución, basada en el concurso de acreedores desde una óptica americana y europea. Finalmente, la normativa americana elude la creación de supervisores públicos independientes, lo que explica el desastre acontecido pues, como indica el Dr. Nasarre, "no puede haber libertad sin regulación".

El Capítulo Tercero se centra en la titulización hipotecaria americana y su refinanciación indefinida, o como alimentar a la bestia de una crisis bancaria sistémica a nivel global que parecía imposible; su preludio fue la crisis de las GSEs en 2003, en la que se produjo una ocultación de deuda y una deficiente gestión del riesgo de los créditos hipotecarios. $O$, como bien indica el Dr. Nasarre, "en la alegalidad está la oportunidad y, claro, el dinero. Lo que a menudo olvidan los comerciantes es que donde está el dinero, también está la responsabilidad". El binomio regulaciónresponsabilidad, desmoralizado con la refinanciación indefinida, volatilizó el sistema y ocasionó la venta masiva de paquetes de hipotecas subprime y la globalización de la crisis bancaria y económica de 2007: se convirtió lo poco líquido en líquido con las MBS, y su titulización en CDOs fue la cadena de transmisión de riesgos y de desaparición de estos préstamos incobrables del balance de las entidades financieras, fomentando su concesión irresponsable. En definitiva, la "modernidad líquida" y su avaricia contaminó de ingentes activos tóxicos y de white down al sistema financiero a nivel mundial. En este sentido, el Dr. Nasarre analiza los problemas de este sistema de traslación del riesgo: el exceso de confianza en las redes de protección que ocasiona en las entidades financieras; la imposibilidad del true sale y la safe harbor; y la inevitable consolidación posterior. Posteriormente, examina los remedios que se plantearon: la Ley DoddFrank de 2010, que guarda ciertos paralelismos con nuestra Directiva 2014/17, y que fue flexibilizada por la Economic Growth Regulatory Relief and Consumer Protection Act; los covered bonds, como alternativa a las MBS que no se han desarrollado; $y$, finalmente, el papel de las agencias de calificación crediticia y la ausencia de responsabilidad por los ratings defectuosos.

La crisis hipotecaria en España, cuyo inicio es global, se ve agudizada por problemas intrínsecos, derivados del "proceso de ensayo-error" legislativo 
como reacción tardía frente a la inacción quinquenal, que provocó una "dispersión legislativa e inseguridad" habitacional. Buena muestra de ello son las desasosegadas reformas en materia de arrendamientos urbanos, cuya calificación de "parcheo" -en el Capítulo Primero- compartimos por sus escasos periodos de vigencia. A ello se dedica el Capítulo Cuarto, titulado "Consecuencias y reacciones a la crisis en España". Más no significa mejor; no se trata de legislar mucho, como en el desconcertante periodo 2011-2017, con medidas dispersas, contradictorias e irreflexivas que dificultaban la tarea de los operadores jurídicos y de los investigadores, sino bien, recordando que la ansiada solución definitiva y estable al problema de la vivienda requiere del jarabe adecuado y la dosis necesaria.

En este Capítulo, se cifran y analizan las consecuencias habitacionales de dicha crisis, ocasionada por el sobreendeudamiento familiar y la voracidad bancaria en la concesión irresponsable de préstamos. Su manifestación más sobrecogerdora socialmente son los lanzamientos de quienes no tienen alternativa habitacional con posterioridad a la ejecución hipotecaria o el desahucio por impago de rentas, de cuyo sinhogarismo libran la solidaridad familiar, el tercer sector y la Administración. Encontramos una pieza clave, frente a la inacción legislativa y pública en el primer lustro de la crisis en el fenómeno "robinprudencial" o la jurisprudencia "robinhoodiana", en aras de la salvaguardia del deudor hipotecario como fórmula alegal para mitigar la asimetría negocial y los abusos financieros. A ello coadyuvaron, tardíamente, diversas medidas de protección del deudor hipotecario y la jurisprudencia europea de consumo contenidas en el libro. Estos pronunciamientos enmendaron la plana en diversas ocasiones al Tribunal Supremo -siendo paradigmático lo acontecido en las cláusulas suelo- en atención a la necesaria nulidad y retroactividad de aquellas cláusulas declaradas abusivas. Otro eslabón de las reacciones a la crisis en España lo constituye la legislación autonómica de acceso a la vivienda. La solución definitiva al problema de la vivienda no pasa por los múltiples "incentivos negativos", surgidos de la legislación autonómica y recogidos al final del Capítulo Cuarto, de los que destacan soluciones reactivas como el impuesto a las viviendas vacías, la inaplicada -y fracasada- expropiación temporal de viviendas, el alquiler social y el alquiler forzoso de la vivienda deshabitada que, a pesar de su constitucionalidad, coincidimos con el Dr. Nasarre que "su eficacia para contribuir a la mejora sustancial del acceso a la vivienda está aún por ver".

En contraposición con lo acontecido en España, los adjetivos que resumirían los instrumentos habitacionales disponibles en el Derecho comparado y analizados en el Capítulo Quinto, "Un nuevo marco civil para la vivienda", serían los siguientes: pocos y buenos. En este Capítulo se propone y justifica la calificación de la vivienda como un "bien inmueble especial" y se hace hincapié en diversas instituciones comparadas para facilitar su acceso. Debemos destacar aquí el legal transplant de la propiedad temporal y la propiedad compartida en el Libro Quinto del Código Civil de Cataluña, cuya regulación fue propuesta por el Dr. Nasarre, lo que atestigua el trabajo de calado llevado a cabo en la Cátedra UNESCO de Vivienda de la Universidad Rovira i Virgili que dirige, pues sus iniciativas contribuyen a la necesaria 
transferencia de conocimientos y revierten a la sociedad en mejoras legislativas y obras excelentes como la presente monografía. Se ilustra esta concepción en su Capítulo Séptimo, "Reflexiones finales": "la cuádruple hélice: sociedad, empresa, administración y universidad". La shared ownership y el leasehold provienen del programa Low-cost Homeownership, que se aplica exitosamente desde hace décadas en el Reino Unido, junto con otras medidas previstas en el programa. Un apunte, muy necesario, para quienes consideran ideologizadas en un determinado sentido las medidas de acceso a la vivienda, es que estas en particular fueron implementadas por la ex Primera Ministra británica, Margaret Thatcher, lo que excluye cualquier sospecha de colectivización; son, pues, fórmulas para facilitar y garantizar una necesidad humana, básica y universal.

Junto con las tenencias intermedias, el Dr. Nasarre propone la necesidad de una metamorfosis de la Ley de Arrendamientos Urbanos de 1994 a la luz de las regulaciones europeas, pues sus defectos no han sido enmendados en su última reforma, efectuada mediante el Real Decreto-ley 7/2019. Sirva como justificación del rigor de sus observaciones la supervisión que el Dr. Nasarre realizó del Informe de España en el Proyecto Europeo "TENLAW: Tenancy Law and Housing Policy in Multi-level Europe", desarrollado en el periodo 2012-2015 y liderado por el Prof. Dr. Christoph Schmid de la Universidad de Bremen. Finalmente, concluye el Capítulo con unas reflexiones acerca de la vivienda colaborativa como manifestación habitacional de la economía colaborativa, a la que deberemos prestar atención por la influencia de la tecnología blockchain y el crowdfunding inmobiliario.

De los años de crisis hipotecaria vividos ha quedado claro que, como recoge el Dr. Nasarre en el inicio del Capítulo Segundo, "El que toma prestado es siervo del que presta", Proverbios 22:7 (s. X a.C.). Pero, también, que la solución definitiva al problema de la vivienda pasa por la redistribución de los distintos regímenes de tenencia, el surgimiento o legal transplant de instituciones de Derecho comparado exitosas, la mejora de la asequibilidad, la eliminación de la infravivienda, la protección al consumidor de préstamos hipotecarios y de arrendamiento de vivienda habitual, y el definitivo abandono de una política de vivienda cortoplacista vinculada a un contexto económico concreto. Este último punto debería urgir a los poderes públicos, porque se demuestra nuevamente ineficaz para hacer frente a las necesidades habitacionales originadas por el COVID-19, previendo una moratoria temporal de los préstamos hipotecarios y dejando al arbitrio de las partes -o, mejor dicho, del arrendador- una solución para el arrendamiento. El Dr. Nasarre ha advertido, con posterioridad a la publicación de este libro, que la crisis económica surgida del COVID-19 va a incrementar el precio del alquiler. Ello puede conducir a una nueva burbuja arrendaticia que ponga contra las cuerdas a los poderes públicos ante la falta de alternativas habitacionales, en una recesión económica mundial cuyo impacto se prevé tres veces superior a la última y sin precedentes desde el Crac de 1929, y cuyas consecuencias requieren de soluciones a la altura de las circunstancias. Obras científicas del nivel de esta monografía contribuyen a aprender del pasado y ofrecen medidas para 
el futuro. Por ello, recomendamos vivamente su atenta lectura y toma en consideración, al tiempo que estamos convencidos que el Dr. Nasarre alumbrará nuevas alternativas para los problemas habitacionales de esta nueva crisis en futuros trabajos.

Cristina Argelich Comelles Doctora en Derecho Civil Universidad de Cádiz cristina.argelich@uca.es 